\title{
METODE SPARSE GRUP LASSO UNTUK MEMODELKAN KECENDERUNGAN PERILAKU SEKSUAL REMAJA PUTRI DI PROVINSI BENGKULU
}

\author{
Hengki Muradii'), Khairil Anwar Notodiputro' ${ }^{2)}$, Bagus Sartono ${ }^{3)}$ \\ ${ }^{1)}$ Departemen Matematika Institut Sains Dan Teknologi Nasional, Jl. Moh Kahfi II, \\ Jakarta Selatan; hengki.muradi@istn.ac.id \\ 2)Departemen Statistika Institut Pertanian Bogor, Jl. Raya Dramaga, \\ Bogor;khairil@apps.ipb.ac.id \\ 2)Departemen Statistika Institut Pertanian Bogor, Jl. Raya Dramaga, Bogor; \\ bagusco@gmail.com
}

\begin{abstract}
The combination of the lasso variable selection method and the lasso group results in a variable selection method that can overcome problems in both the lasso method and the lasso group. This combination can also be applied to the cases of nonorthogonal groups as required in the lasso group method. This paper discusses the lasso sparse method with the coordinate descent approach as proposed by Friedman, et.al (2010). The real case raised in this study is the tendency of the sexual behaviour of young women in Bengkulu province. Because there are 15 explanatory variables for $\mathrm{X}$, a variable selection process is needed to obtain the simplest model. The results were selected as many as 3 explanatory variables so that the remaining 12 explanatory variables can then be modelled in logistic regression. The substance of the unselected regression parameters is young women with more high school education, living in rural areas, rarely reading newspapers/magazines, rarely accessing the internet $>1$ time a month, and strongly agree with virginity more likely to engage in sexual activity compared with educational characteristics, residence, newspaper reading intensity, internet access, and other virginity attitudes.
\end{abstract}

Keywords. Lasso, lasso groups, Sparse grup lasso, Sexual behavior, Models

\section{Pendahuluan}

Metode grup lasso merupakan perluasan dari metode lasso yang bertujuan untuk menyeleksi sekumpulan peubah penjelas dalam model, khususnya pada kasus banyaknya penjelas jauh lebih besar daripada banyaknya mengamatan $(\mathrm{p} \gg \mathrm{n})$. Grup lasso dimulai dengan membuat kelompokkelompok dari sekumpulan peubah, kemudian diseleksi. Yuan \& Lin (2007) berhasil memformulasikan algoritma metode grup lasso yang cara kerjanya

Euclid, p-ISSN 2355-1712, e-ISSN 2541-4453, Vol. 7, No. 1, pp. 1- 76

(CLembaga Penelitian Universitas Swadaya Gunung Jati (UGJ), Cirebon. 
sama dengan metode lasso pada level grup. Pada level grup, optimasi bergantung pada parameter tuning $\lambda$. Jika $\lambda=0$ maka seluruh parameter dalam grup dieliminasi.

Menurut Friedman, et.al (2010) untuk metode grup lasso yang tidak mengalami sparsitas, jika parameter 1 pada level grup bernilai nol maka seluruh parameter dalam grup akan tereliminasi. Karena itu diusulkan penambahan penalty pada grup lasso sehingga terdapat sparsitas dalam grup. Metode ini disebut dengan metode Sparse Group Lasso (SGL).

Metode SGL merupakan kombinasi dari lasso dan grup lasso. Friedman, et.al (2010) menyatakan bahwa algoritma SGL mampu menangani permasalahan sparsitas dan dapat bekerja pada kondisi matriks kovariat tidak ortonormal. Untuk mendukung pernyataan tersebut, Friedman, et.al (2010) membuat simulasi dengan data bangkitan sebanyak 200 observasi dan 100 peubah penjelas. Hasilnya menunjukkan bahwa metode SGL lebih efektif dibandingkan metode lasso dan grup lasso. Sayangnya, hasil implementasi data simulasi tidak selalu sejalan dengan kasus nyata. Oleh karena itu, dalam penelitian ini akan diimplementasikan metode sparse grup lasso untuk kasus pemodelan kecenderung perilaku seksual pada remaja putri.

\section{Metode Penelitian}

\subsection{Data Penelitian}

Data penelitian yang digunakan pada penelitian ini adalah data SDKI tahun 2017 di provinsi Bengkulu. Peubah respon adalah pengakuan responden remaja putri yang berusia 15-24 tahun tentang bagaimana mereka berperilaku pada saat berinteraksi berdua dengan pasangannya sebelum menikah. Kovariat yang dimasukkan ke dalam proses peubah adalah pendidikan tertinggi, daerah tempat tinggal, intensitas membaca surat kabar/majalah, intensitas mengakses internet, alkohol, dan pandangan terhadap keperawanan. Secara rinci peubah-peubah tersebut disajikan pada Tabel 1 berikut ini. 
Tabel 1. Peubah yang digunakan dalam pemodelan

\begin{tabular}{|c|c|c|c|}
\hline Peubah & Notasi & Kategori & $\begin{array}{l}\text { Skala } \\
\text { Ukur }\end{array}$ \\
\hline Perilaku Seksual Remaja Putri & $y$ & $\begin{array}{l}0=\text { Berpegangan tangan } \\
\text { atau berpelukan } \\
1=\text { Berciuman atau } \\
\text { meraba }\end{array}$ & Nominal \\
\hline Pendidikan Tertinggi & $X_{1}$ & $\begin{array}{l}1=\mathrm{SD} \\
2=\mathrm{SMP} \\
3=\mathrm{SMA} \\
4=\mathrm{PT}\end{array}$ & Ordinal \\
\hline Daerah Tempat Tinggal & $X_{2}$ & $\begin{array}{l}0=\text { Perdesaan } \\
1=\text { Perkotaan }\end{array}$ & Nominal \\
\hline $\begin{array}{l}\text { Intensitas Membaca Surat } \\
\text { Kabar/Majalah }\end{array}$ & $X_{3}$ & $\begin{array}{l}\text { 1 = Paling Sedikit } \\
\text { Seminggu Sekali } \\
\text { 2= Jarang } \\
\text { 3. Tidak Pernah }\end{array}$ & Nominal \\
\hline Intensitas Akses Internet & $X_{4}$ & $\begin{array}{l}\text { 1= Hampir Setiap Hari } \\
2 \text { = Paling Sedikit } \\
\text { Seminggu sekali } \\
3 \text { = Paling Sedikit Sekali } \\
\text { Sebulan } \\
4 \text { = Tidak sama sekali }\end{array}$ & Nominal \\
\hline Sikap Terhadap Keperawanan & $X_{5}$ & $\begin{array}{l}0=\text { Sangat Setuju } \\
1=\text { Setuju } \\
2=\text { Tidak Setuju }\end{array}$ & Ordinal \\
\hline
\end{tabular}

\subsection{Model Regresi Logistik}

Berdasarkan sebaran peubah respon yakni binomial, maka model yang akan dibangun adalah model regresi logistik, yaitu:

$$
\log \left(\frac{\pi}{1-\pi}\right)=\beta_{0}+\beta_{1} X_{1}+\beta_{2} X_{2}+\beta_{3} X_{3}+\beta_{4} X_{4}+\beta_{5} X_{5}
$$

Dimana $\pi$ merupakan probabilitas kejadian sukses dari peubah respon (McCullagh \& Nelder, 1983). Peubah $X_{1}$ adalah pendidikan tertinggi remaja putri, $X_{2}$ adalah daerah tempat tinggal, $X_{3}$ merupakan intensitas membaca surat kabar/majalah, $X_{4}$ adalah intensitas mengakses internet, dan $X_{5}$ adalah sikap terhadap keperawanan. 
Seluruh peubah prediktor merupakan kategorik sehingga dalam analisis data didefinisikan peubah dummy yang berjumlah sebanyak 15 peubah dummy. Peubah pendidikan $\left(X_{1}\right)$ didumikan menjadi empat peubah dummy, peubah $X_{2}$ menjadi satu peubah dummy, peubah $X_{3}$ didummikan menjadi 3 vaiabel dummy, peubah $X_{4}$ dibuat menjadi tiga peubah dummy, dan peubah $X_{5}$ menjadi tiga peubah dummy.

\subsection{Tahapan Analisis Data}

1. Eksplorasi data yang berkaitan dengan model penelitian

2. Cleaning data dari missing value.

3. Input data ke aplikasi R.

4. Paket di R yang digunakan untuk analisis data adalah paket SGL dengan cara kerja sebagai berikut:

a. Nilai awal : $\hat{\beta}=\beta_{0}$

Pada grup $l$ didefinisikan residual

$$
\begin{aligned}
& \boldsymbol{r}_{l}=y-\sum_{k \neq l} X_{k} \beta_{k} \\
& \boldsymbol{r}_{j}=\boldsymbol{y}^{\prime}-\sum_{k \neq j} Z_{k} \theta_{k}
\end{aligned}
$$

a) $\operatorname{Jika} J(\hat{t})=\sum_{j=1}^{k} s_{j}^{2} \leq 1$ maka $\hat{\beta}=\beta_{0}$.

b) Jika $J(\hat{t})>1$ maka

- $\quad$ Jika $\left|Z_{j}^{T} r_{j}\right|<\lambda_{2} \operatorname{maka} \hat{\theta}_{j}=0$

- Jika $\left|Z_{j}^{T} r_{j}\right| \geq \lambda_{2}$ maka minimalisasi fungsi:

$$
\frac{1}{2} \sum_{i=1}^{N}\left(y_{i}^{\prime}-\sum_{j=1}^{k} Z_{i j} \theta_{j}\right)^{2}+\lambda_{1}|| \theta \|_{2}+\lambda_{2} \sum_{j=1}^{k}\left|\theta_{j}\right|
$$

6. Ulangi (2) sampai grup-grup $l$ konvergen 


\section{Hasil dan Pembahasan}

Secara deskriptif perilaku seksual dan kovariatnya dapat dilihat pada tabel 2 berikut ini:

Tabel 2. Gambaran Perilaku seksual remaja Putri dan Kovariatnya

\begin{tabular}{|c|c|c|c|}
\hline Peubah & Kategori & Frekuensi & $\%$ \\
\hline \multirow{3}{*}{$\begin{array}{l}\text { Perilaku Seksual Remaja } \\
\text { Putri }\end{array}$} & Tidak pacaran, Berpengangan & 114 & 90,48 \\
\hline & Tangan atau Berpelukan & & \\
\hline & Berciuman atau meraba & 12 & 9,52 \\
\hline \multirow[t]{4}{*}{ Pendidikan Tertinggi } & SD & 3 & $2.38 \%$ \\
\hline & SMP & 15 & $11.90 \%$ \\
\hline & SMA & 60 & $47.62 \%$ \\
\hline & PT & 48 & $38.10 \%$ \\
\hline \multirow[t]{2}{*}{ Daerah Tempat Tinggal } & Perdesaan & 59 & $46.83 \%$ \\
\hline & Perkotaan & 67 & $53.17 \%$ \\
\hline \multirow{3}{*}{$\begin{array}{l}\text { Intensitas Membaca Surat } \\
\text { Kabar/Majalah }\end{array}$} & Paling Sedikit Seminggu Sekali & 39 & $30.95 \%$ \\
\hline & Jarang & 59 & $46.83 \%$ \\
\hline & Tidak pernah & 28 & $22.22 \%$ \\
\hline \multirow[t]{3}{*}{ Intensitas Akses Internet } & Hampir Setiap Hari & 84 & $75.7 \%$ \\
\hline & $>1$ kali seminggu & 20 & $18.0 \%$ \\
\hline & $>1$ kali sebulan & 7 & $6.3 \%$ \\
\hline \multirow{3}{*}{$\begin{array}{l}\text { Sikap Terhadap } \\
\text { Keperawanan }\end{array}$} & Sangat Setuju & 91 & $72.22 \%$ \\
\hline & Setuju & 34 & $26.98 \%$ \\
\hline & Tidak Setuju & 1 & $0.79 \%$ \\
\hline
\end{tabular}

Berdasarkan perilaku seksual diperoleh data bahwa dari 126 remaja putri di Provinsi Bengkulu yang di survei pada tahun 2017, sebanyak 114 responden $(90,48 \%)$ mengakui hanya melakukan kegiatan berpegangan tangan atau berpelukan sedangkan 12 responden (9,52\%) lainnya melakukan kegiatan berciuman dan meraba. Kegiatan berpegangan tangan atau berpelukan termasuk perilaku seksual ringan sedangkan kegiatan berciuman dan meraba merupakan perilaku seksual berat.

Pada proses seleksi peubah menggunakan metode sparse lasso, digunakan paket SGL yang dibangun oleh Simon.et.al (2018). Paket SGL tersebut dapat mengakomodasi model linear, logistic, dak Cox. Hasil seleksi peubah menggunakan metode seleksi sparse grup lasso adalah sebagai berikut: 
Tabel 3. Hasil Seleksi Peubah Dengan Metode Sparse Grup Lasso

\begin{tabular}{llcc}
\hline \multirow{2}{*}{ Peubah } & \multicolumn{1}{c}{ Dummy Peubah } & \multicolumn{2}{c}{ Parameter $\boldsymbol{\beta}$} \\
\cline { 2 - 4 } & & $\begin{array}{c}\text { Initial } \\
\text { Value }\end{array}$ & $\begin{array}{c}\text { Hasil } \\
\text { Akhir }\end{array}$ \\
\hline Pendidikan Tertinggi & SD & 0 & $-6,129$ \\
\cline { 2 - 4 } & SMP & 0 & $-0,298$ \\
\cline { 2 - 4 } & SMA & 0 & 4,790 \\
\cline { 2 - 4 } & PT & 0 & 0,000 \\
\hline Daerah Tempat Tinggal & Perdesaan & 0 & 1,956 \\
\cline { 2 - 4 } Intensitas Membaca Surat & Perkotaan & 0 & $-1,398$ \\
Kabar/Majalah & Paling Sedikit Seminggu & 0 & 0,000 \\
& Sekali & & \\
\cline { 2 - 4 } & Jarang & 0 & 2,224 \\
\cline { 2 - 4 } & Tidak pernah & 0 & $-7,660$ \\
\hline Intensitas Akses Internet & Hampir Setiap Hari & 0 & $-3,584$ \\
\cline { 2 - 4 } & $>1$ kali seminggu & 0 & 6,161 \\
\cline { 2 - 4 } & $>1$ kali sebulan & 0 & 0,328 \\
\hline Sikap Terhadap & Sangat Setuju & 0 & $-0,587$ \\
\cline { 2 - 4 } Keperawanan & Setuju & 0 & 0,000 \\
\cline { 2 - 4 } & Tidak Setuju & & 0 \\
\hline
\end{tabular}

Pada Tabel 3 dapat dilihat bahwa dari 15 peubah dummy yang diseleksi, diperoleh hasil bahwa dengan cara mengelompokkan peubah penjelas menjadi kelompok-kelompok yang berangotakan tiga peubah, terdapat tiga peubah dummy yang terseleksi yaitu pendidikan perguruan tinggi, intensitas membaca surat kabar/majalah paling sedikit seminggu sekali, dan peubah dummy sikap tidak setuju terhadap keperawanan. Jumlah iterasi yang di setting secara default oleh $\mathrm{R}$ adalah sebanyak 1000 iterasi yang menghasilkan parameter lambda $(\lambda)$ sebesar 0,00022 .

Dalam penelitian ini dilakukan uji coba dengan mengatur jumlah anggota masing-masing kelompok dengan berbagai macam variasi, yakni 1 anggota, 2 anggota, 4 anggota, dan 5 anggota. Hasilnya diperoleh bahwa walaupun jumlah anggota kelompok berbeda-beda namun hasilnya tetap konsisten. 
Hasil penelitian ini menunjukkan bahwa metode sparse grup lasso dapat diimplementasikan dalam prosedur seleksi peubah. Menurut Fonti (2017), prosedur seleksi peubah sangat penting dan menantang dalam pemodelan, terutama karena output yang diinginkan bervariasi untuk set data yang berbeda, dan sulit untuk menemukan model yang bekerja untuk setiap jenis masalah. Tugas menjadi lebih menantang ketika berhadapan dengan dataset dimensi tinggi.

Berdasarkan koefisien model regresi logistik yang diperoleh dari proses seleksi sparse grup lasso dapat dijelaskan bahwa berdasarkan pendidikan, remaja putri yang berpendidikan SMA lebih berpeluang melakukan aktivitas seksual berupa berciuman atau meraba dibandingkan dengan remaja putri yang berpendidikan SD maupun SMP. Berdasarkan daerah tempat tinggal, remaja putri yang tinggal di perdesaan lebih berpeluang melakukan aktivitas seksual dibandingkan dengan remaja putri yang tinggal di perkotaan. Remaja putri yang jarang membaca lebih berpeluang melakukan aktivitas seksual dan remaja putri yang mengakses internet $>1$ kali dalam satu bulan lebih berpeluang dibandingkan dengan remaja putri yang lebih intens dalam mengakses internet. Dan remaja putri yang sangat setuju dengan keperawanan justru lebih berpeluang melakukan aktivitas seksual dibandingkan dengan remaja putri yang setuju dengan keperawanan.

\section{Diskusi}

Dalam penelitian ini, parameter tuning $(\lambda)$ di set $\lambda_{1}=\lambda_{2}$. Akan menjadi lebih menarik jika parameter tuning ini di set tidak sama. Efek dari pengaturan tersebut menarik untuk diteliti, apakah akan memberikan hasil seleksi optimal yang sama. 
Berkaitan dengan matriks kovariat, dalam penelitian ini masing-masing grup berisi vektor-vektor yang saling orthogonal. Friedman, et.al (2010) mengklaim bahwa algoritama sparse grup lasso yang di usulkannya mampu di implementasikan pada kasus dimana vektor-vektor yang tidak saling orthogonal. Karena itu, penelitian yang mengimplementasikan kasus dimana vektor-vektor yang tidak saling orthogonal dapat membuktikan klain tersebut.

\section{Kesimpulan dan Saran}

Metode seleksi sparse grup lasso dengan menggunakan pendekatan coordinate descent dapat diimplementasikan pada kasus regresi logistik. Dalam penelitian ini, dari 20 peubah yang di seleksi terdapat 3 peubah yang terseleksi dengan nilai parameter tuning $\lambda=0,00022$. Ketiga variabel yang terseleksi adalah pendidikan PT, intensitas membaca surat kabar paling sedikit satu kali satu minggu, dan sikap tidak setuju terhadap keperawanan.

Penelitian ini fokus kepada implementasi metode seleksi sparse grup lasso dengan asumsi bahwa matriks kovariat bersifat orthogonal. Friedman, et.al (2010) mengklaim bahwa algoritma yang sparse grup lasso yang ia diusulkan mampu mengakomodasi pada model dengan asumsi bahwa matriks kovariat tidak orthogonal. Oleh karena disarankan kepada peneliti berikutnya untuk dapat memvalidasi klaim tersebut dengan melakukan implementasi pada kasus real.

\section{Daftar Pustaka}

Bakin, S. 1999. Adaptive regression and model selection in data mining problems. PhD Thesis. Australian National University, Canberra.

Jerome Friedman, Trevor Hastie, \& Robert Tibshirani. 2010. A note on the group lasso and a sparse group lasso. arXiv: 1001.0736v1. 
McCullagh, P \& J.A. 1983. Nelder FRS. Generalized Linear Models; Second edition. London: Chapman and Hall.

Noah Simon, Jerome Friedman, Trevor Hastie, and Rob Tibshirani. 2018. Package'SGL'.CRAN Documentation.

Sarwono. 2007. Psikologi Remaja. Jakarta : Raja Grafindo Persada.

Tjiptaningrum, R. 2009. Psikologi Remaja dan Kesehatan Reproduksi. Jakarta: Grafindo Persada.

Valeria Fonti. 2017. Feature Selection using LASSO. Research Paper in Business Analytics VU Amsterdam.

Yuan, M. \& Lin, Y. 2007. Model selection and estimation in regression with grouped variables. Journal of the Royal Statistical Society, Series B 68 (1), 49-67. 